This is an electronic reprint of the original article. This reprint may differ from the original in pagination and typographic detail.

Author(s): Mikkola, Tuija; Heinonen, Ari; Kovanen, Vuokko; Cheng, Sulin; Kujala, Urho; Suominen, Harri; Alén, Markku; Puolakka, Jukka; Ankarberg-Lindgren, Carina; Ronkainen, Paula; Koskenvuo, Markku; Kaprio, Jaakko; Rantanen, Taina; Sipilä, Sarianna

Title: Influence of long-term postmenopausal hormone replacement therapy on estimated structural bone strength: A study in discordant monozygotic twins.

Year: $\quad 2011$

Version:

Please cite the original version:

Mikkola, T., Heinonen, A., Kovanen, V., Cheng, S., Kujala, U., Suominen, H., Alén, M., Puolakka, J., Ankarberg-Lindgren, C., Ronkainen, P., Koskenvuo, M., Kaprio, J., Rantanen, T., \& Sipilä, S. (2011). Influence of long-term postmenopausal hormone replacement therapy on estimated structural bone strength: A study in discordant monozygotic twins.. Journal of Bone and Mineral Research, 26(3), 546-552. https://doi.org/10.1002/jbmr.255

All material supplied via JYX is protected by copyright and other intellectual property rights, and duplication or sale of all or part of any of the repository collections is not permitted, except that material may be duplicated by you for your research use or educational purposes in electronic or print form. You must obtain permission for any other use. Electronic or print copies may not be offered, whether for sale or otherwise to anyone who is not an authorised user. 
This is the accepted version of the following article: "Mikkola et al. Influence of Long-Term Postmenopausal Hormone Replacement Therapy on Estimated Structural Bone Strength: A Study in Discordant Monozygotic Twins. Journal of Bone and Mineral Research, Volume 26, Issue 3, March 2011, Pages: 546-552,”, which has been published in final form at http://onlinelibrary.wiley.com/doi/10.1002/jbmr.255/abstract."

\section{Influence of Long-Term Postmenopausal Hormone Replacement Therapy on Estimated Structural Bone Strength: A Study in Discordant Monozygotic Twins}

Tuija M. Mikkola ${ }^{1,2}$, Ari Heinonen ${ }^{1}$, Vuokko Kovanen ${ }^{1}$, Sulin Cheng $^{1}$, Urho M. Kujala ${ }^{1}$, Harri Suominen ${ }^{1}$, Markku Alén ${ }^{1,3}$, Jukka Puolakka ${ }^{4}$, Carina Ankarberg-Lindgren ${ }^{5}$, Paula H. A. Ronkainen $^{1,2}$, Markku Koskenvuo ${ }^{6}$, Jaakko Kaprio ${ }^{6,7,8}$, Taina Rantanen ${ }^{1,2}$, Sarianna Sipilä ${ }^{1,2}$

${ }^{1}$ Department of Health Sciences, University of Jyväskylä, Jyväskylä, Finland; ${ }^{2}$ Gerontology Research Centre, University of Jyväskylä, Jyväskylä, Finland ${ }^{3}$ Department of Medical Rehabilitation, Oulu University Hospital, Oulu, Finland; ${ }^{4}$ Central Finland Health Care District, Jyväskylä, Finland; ${ }^{5}$ Department of Pediatrics, Sahlgrenska Academy at University of Gothenburg, Gothenburg, Sweden; ${ }^{6}$ Department of Public Health, University of Helsinki, Helsinki, Finland; ${ }^{7}$ Institute for Molecular Medicine, Helsinki, Finland; ${ }^{8}$ National Institute for Health and Welfare, Helsinki, Finland

Funding sources: The Finnish Ministry of Education, the Academy of Finland, the Finnish Cultural Foundation, Yrjö Jahnsson Foundation and National Graduate School of Musculoskeletal Disorders and Biomaterials

Running title: Postmenopausal hormone therapy and bone 
E-mail addresses: tuija.m.mikkola@jyu.fi, ari.heinonen@jyu.fi,vuokko.kovanen@jyu.fi, sulin.cheng@jyu.fi, urho.m.kujala@jyu.fi, harri.suominen@jyu.fi, markku.alen@ppshp.fi, jukka.puolakka@ksshp.fi, carina.ankarberg-lindgren@vgregion.se,

paula.h.a.ronkainen@jyu.fi, markku.koskenvuo@helsinki.fi, jaakko.kaprio@helsinki.fi, taina.rantanen@jyu.fi, sarianna.sipila@jyu.fi

\section{Corresponding author:}

Tuija M Mikkola

Gerontology Research Centre

P.O.Box 35 (Viv)

FI-40014 University of Jyväskylä

Finland

tel. +358142602149

fax +358142604600

tuija.m.mikkola@jyu.fi

Number of words/characters in manuscript: $4713 / 26558$

Number of words/characters in abstract: 238/1 295

Number of figures: 3 black/white 


\section{CONFLICT OF INTEREST}

All authors have no conflicts of interest.

\section{The roles of the authors:}

SS, VK, MA, MK and JK participated in the study design. TMM, AH, VK, SC, UMK, HS, MA, JP, PHAR, TR and SS participated in the data collection. CA-L participated in the hormone determination. TMM, AH and SS analysed the data. TMM, AH, VK, SC, UMK, HS, MA, CA-L and PHAR interpreted the data. TMM, AH and SS drafted the manuscript and VK,

SC, UMK, HS, MA, JP, CA-L, PHAR, MK, JK and TR critically revised it. All the authors approved the final version of the manuscript. 


\section{ABSTRACT}

Although postmenopausal hormone replacement therapy (HRT) is known to prevent fractures, knowledge on the influence of long-term HRT on bone strength and its determinants other than areal bone mineral density is scarce. This study used a genetically controlled design with 24 monozygotic female twin pairs aged 54 to 72 years in which one co-twin was using HRT (mean duration 8 years) and the other had never used HRT. Estimated bone strength, crosssectional area, volumetric mineral density, bone mineral mass as well as cross-sectional density and mass distributions were assessed in the tibial shaft, distal tibia, and distal radius with peripheral computed tomography (pQCT). In the tibial shaft, HRT users had $9 \%(95 \%$ CI: $3-15 \%$ ) higher estimated bending strength than their non-using co-twins. Larger cortical area and higher cortical bone mineral density accounted for this difference. The cortex was larger in the HRT users in the endocortical region. In the distal tibia, estimated compressive strength was $24 \%(9-40 \%)$ higher and in the distal radius $26 \%(11-41 \%)$ higher in the HRT users compared to their non-using co-twins due to higher volumetric bone mineral density. No difference between users and non-users was observed in total bone crosssectional area in any measured bone site. The added mineral mass in the HRT users was distributed evenly within and between bone sites. In postmenopausal women, long-term HRT preserves estimated bone strength systemically by preventing bone mineral loss similarly in body weight-loaded and non weight-loaded bone.

Key words: Bone, postmenopausal women, hormone replacement therapy, mechanical loading, pQCT 


\section{INTRODUCTION}

Menopause-related estrogen deficiency accelerates loss of bone mineral mass and deterioration of bone macrostructure. ${ }^{(1,2)}$ Both bone mineral mass and bone structure are important determinants of bone strength, ${ }^{(3)}$ and deterioration in these properties increase fracture risk in postmenopausal women. ${ }^{(4)}$ Postmenopausal hormone replacement therapy (HRT) can counteract the increased fracture risk, a phenomenon which is partly explained by reduced bone resorption ${ }^{(5)}$ leading to the accrual of bone mineral mass. ${ }^{(6,7)}$ However, it has been shown that estrogen inhibits periosteal apposition (i.e. increase in bone outer

diameter), ${ }^{(8-11)}$ which has adverse effects on bone strength. The effects of HRT on bone have predominantly been studied with planar methodology, and therefore it remains unclear how HRT influences the bone macrostructure and thus bone strength.

Present knowledge on the short-term effects of HRT on areal bone mineral density (areal BMD) derives from numerous randomized controlled trials. Previous follow-up studies indicate that HRT has a cumulative positive effect on areal BMD. ${ }^{(6,12)}$ This suggests that the potential of HRT to improve bone properties in the longer term is greater than has been observed during only a few years of use. Although randomized controlled trials are valued, long-term trials studies are difficult to conduct and thus often cannot provide reliable information on long-term treatment effects.

The purpose of this study was to investigate the influence of long-term HRT on estimated bone strength and its important determinants — cross-sectional macrostructure, volumetric bone mineral density (volumetric BMD), mineral mass, and distribution of bone mineral in postmenopausal monozygotic twins discordant for HRT use over a long period. To 
investigate whether the influence of HRT is different in body weight-loaded and non-weightloaded bone, we examined lower and upper limb bones, including a diaphyseal bone site containing mostly cortical bone and epiphyseal bone sites containing both cortical and trabecular bone. Since estrogen suppresses bone remodeling and especially bone resorption we hypothesized that the HRT users have higher estimated bone strength than the non-users in all the bone sites due to higher bone mineral density and higher amount of bone mineral at the endocortical surface in the diaphyseal bone.

\section{METHODS}

\section{Design}

This study uses a co-twin control design. It is a retrospective cohort design in which the control subjects are monozygotic co-twins of the exposed subjects. This design has the advantage of controlling for both genetic and multiple environmental factors that are shared by the co-twins. These factors account for more than $70 \%$ of the variance in bone structural strength, volumetric BMD and macrostructure. ${ }^{(13,14)}$ Therefore, the analyses of a co-twin control study are powerful even with a low number of subjects. The design also enables investigation of long-term exposures.

\section{Participants}

Two existing datasets on postmenopausal female twin pairs, drawn from the same population-based, nationwide Finnish Twin Cohort Study consisting of twins born before 1958, were used. ${ }^{(15)}$ The first study, FITSA, ${ }^{(16)}$ is a study of genetic and environmental effects on the disablement process in older women with extensive data collected from 103 
monozygotic and 114 dizygotic female twin pairs aged 63 to 76 years. The second study, SAWEs, ${ }^{(17)}$ analyzes data on 15 monozygotic female twin pairs aged 54 to 62 years and discordant for HRT. They were recruited by asking female twin pairs with suitable birth years to self-identify themselves as discordant for HRT use. The zygosity of the twin pairs was confirmed using a battery of ten highly polymorphic gene markers. Twin pairs in which one sister had been a current HRT user for at least the previous 12 months and the other sister had never used HRT, were identified from these two studies. Subjects with bone diseases or medication affecting bone metabolism were excluded. In total, 24 monozygotic pairs discordant for HRT, nine from FITSA and 15 from SAWEs, were studied. The studies were approved by the Ethics Committee of the Central Finland Hospital. Before the laboratory examinations, the subjects provided a written informed consent. The study measurements were conducted blind to HRT use.

Mean age of initiation of HRT use was 53 (SD 6.5) and the mean duration of HRT use was 8.3 years (SD 5.7). Twelve women used estradiol only, eight estradiol and progesterone, and four products containing tibolone. One of the co-twins classified as a non-user had used HRT for 3 months 7 years prior to the laboratory measurements. Mean age at last menstruation was 50 (SD 3.6) for HRT users and 50 (3.5) for non-users. Five HRT users and three non-users were smokers. Thirteen of the HRT co-twins were physically active, nine moderately active, and two sedentary. The corresponding numbers for non-HRT co-twins were twelve, ten, and two. 


\section{Clinical examination}

Self-reported HRT use, age at last menstruation, gynecological surgery, and acute and chronic illnesses were elicited by a questionnaire and confirmed by a physician during the clinical examination.

\section{Bone assessments}

Peripheral quantitative computed tomography scans (pQCT, XCT 2000, Stratec Medizintechnik GmbH, Pforzheim, Germany) were obtained from the side of the dominant hand. The scanned sites were 55\% (tibial shaft) and 5\% (distal tibia) of the tibial length proximal to the distal end of the tibia. In the radius, the scanned site was $4 \%$ of the length of the segment proximal to the distal end of radius. The analysis of the pQCT images was performed as described earlier. ${ }^{(13,14)}$ Bone mineral mass $(\mathrm{mg} / \mathrm{mm})$, total cross-sectional area (A, $\mathrm{mm}^{2}$, including bone marrow area), cortical volumetric BMD $\left(\mathrm{mg} / \mathrm{cm}^{3}\right)$, cortical crosssectional area $\left(\mathrm{mm}^{2}\right)$, cross-sectional area of bone marrow $\left(\mathrm{mm}^{2}\right)$, proportion of cortical bone of total cross-sectional area, and bone bending strength index (i.e. section modulus, BSIbend $)^{(14)}$ were analyzed for the tibial shaft. Bone bending strength index was calculated as

$$
\text { BSIbend }=\left(\int \rho \mathrm{y}^{2} \mathrm{dA}\right) / \sqrt{ } \mathrm{A} \text {, }
$$

where where $\rho$ is the mineral density of an area unit, $y$ is the distance from the centre of mass and $\mathrm{A}$ is the bone area. For the distal tibia and distal radius, bone mineral mass, total crosssectional area, total volumetric BMD $\left(\mathrm{mg} / \mathrm{cm}^{3}\right)$, trabecular volumetric BMD $\left(\mathrm{mg} / \mathrm{cm}^{3}\right)$, and compressive bone strength index (BSIcomp, $\mathrm{g}^{2} / \mathrm{cm}^{4}$ ) were analyzed. Compressive bone strength index (BSIcomp) ${ }^{(13)}$ was calculated as

$$
\text { BSIcomp }=\mathrm{BMD}^{2} \cdot \mathrm{ToA} \text {. }
$$

For each bone site, radial distribution of volumetric BMD and polar distribution of bone mineral mass were analyzed. The radial distribution analysis expresses volumetric BMD as a 
function of the distance from the centre of bone mass. In this analysis, nine out of ten regions are presented due to partial volume effect on the outermost region. In addition for the tibial shaft, the results are shown for regions with a group mean higher than $100 \mathrm{mg} / \mathrm{cm}^{3}$ to exclude the bone marrow area. The polar distribution analysis gives bone mineral mass as an angular distribution for 72 sectors around the centre of bone mass. In the present study, the sectors were grouped into eight sectors. Valid data were obtained on the tibial shaft for 21 pairs, on the distal tibia for 23 pairs and on the distal radius for 22 pairs. Reasons for excluding bone measurements were substantial movement artifacts, previous fracture in the scanned site, and inability to fit the leg into the gantry of the pQCT device.

\section{Hormone analysis}

Serum estradiol levels were determined in duplicate by extraction RIA as previously described. ${ }^{(17,18)}$ Serum sex hormone binding globulin (SHBG) levels were determined using solid-phase, chemiluminescent immunometric assay (Immulite ${ }^{\circledR} 1000$ SHBG, Diagnostic Products Corporation, Los Angeles, USA). Free estradiol levels were calculated from 17ßestradiol and SHBG levels according a previously presented method. ${ }^{(19)}$

\section{Body composition and physical activity}

Lean body mass and total body fat were assessed using bioelectrical impedance (Spectrum II;

RJL Systems, Detroit; MI, USA). Physical activity was assessed using the scale by Grimby ${ }^{(20)}$ with slight modifications. ${ }^{(13)}$

\section{Statistical methods}

The influence of exposure to HRT was evaluated by comparing differences in bone properties within the twin pairs using paired-samples t-test. In cases of non-normal distribution in the 
intra-pair differences, the Wilcoxon signed ranks test was used. Mean intra-pair differences $(\mathrm{IPD} \%=$ HRT user/non-user*100-100) with 95\% confidence intervals (CI) were calculated. To evaluate the temporal trend in the intra-pair difference, regression analyses were performed between time since menopause in the non-user co-twin and intra-pair difference in bone strength between the co-twins in each bone site. The level of significance was set at $\mathrm{p}<0.05$.

\section{RESULTS}

Anthropometry, body composition, and serum hormone concentrations

No significant differences were observed in anthropometry or body composition between the HRT users and non-users (Table 2). As expected, HRT users had significantly higher serum total estradiol, free estradiol, and SHBG concentrations (Table 2).

\section{Diaphyseal bone}

The HRT users had 9\% (95\% CI: 3 to $15 \%)$ higher estimated bending strength in the tibial shaft than their non-using co-twins (Table 1, Figure 1). Bending strength was higher due to

higher cortical volumetric BMD (mean 5\%, 3 to 7\%) and larger cortical area $(8 \%, 2$ to $14 \%)$, which also increased bone mineral mass $(11 \%, 5$ to $16 \%)$. The larger cortical to total area ratio $(6 \%, 1$ to $11 \%)$ in the HRT users than in the non-users together with similar total crosssectional areas in the users and non-users indicates additional bone mineral on the endocortical surface in the HRT users. No significant difference was observed in marrow cavity area between the HRT users and non-users. Volumetric BMD was significantly higher throughout the bone cross-section, from the centre to outer surface, in the HRT users 
compared to non-users except in the innermost area (Fig. 2). The HRT users had significantly higher bone mineral mass than the non-users in all directions (Fig. 3).

\section{Epiphyseal bone}

The HRT users had higher estimated compressive bone strength in the distal tibia $(24 \%, 9$ to $40 \%)$ and distal radius $(26 \%, 11$ to $41 \%)$ than their non-using co-twins. This was due to higher total volumetric BMD $(11 \%, 4$ to $18 \%)$ in the HRT users, since total bone crosssectional area did not differ between the HRT users and non-users. Higher mineral density resulted in higher bone mineral mass in the distal tibia (10\%, 4 to $16 \%)$ and distal radius $(12 \%, 5$ to $18 \%)$. Trabecular density of the distal tibia and radius was $11 \%$ (2 to $19 \%)$ and $22 \%$ ( 7 to $36 \%$ ) higher, respectively, in the HRT users compared to non-users. Volumetric BMD was significantly higher throughout the bone in the HRT users compared to non-users except in the innermost area and in the trabecular area next to the cortical wall (Fig. 2). Bone mineral mass was significantly higher in all eight sectors in both bone sites except for one anterior sector in the distal tibia and two anterior sectors in the distal radius (Fig. 3).

\section{Bone strength and time since menopause}

The longer the time since menopause, the larger was the difference in estimated bone strength between the co-twins. Time since menopause explained $25 \%$ of the variance in distal tibia compressive strength $(\mathrm{p}=0.015)$ and $24 \%$ of that in distal radius compressive strength $(p=0.021)$. The slopes of the regression lines corresponded to a 2.8 and $2.6 \%$ increase in the intra-pair difference per year since menopause in the distal tibia and radius, respectively. 


\section{DISCUSSION}

This genetically controlled study showed that in the diaphyseal site, the higher estimated bending strength in the HRT-users compared to non-users resulted from the higher volumetric BMD and larger cross-sectional area of the cortex. In the epiphyseal bone sites, higher estimated compressive strength was due to higher volumetric BMD. The extra mineral mass in the HRT-using twins was distributed evenly within and between bone sites.

The differences in bone strength between HRT users and non-users in the present study were marked: $9 \%$ in the diaphyseal bone site and over $20 \%$ in the epiphyseal bone sites. Such advantages in bone strength (half a SD) in HRT users are likely to decrease the risk of fracture substantially. Szulc et al. ${ }^{(2)}$ reported that a 1 SD decrease in estimated bone strength doubles the fracture risk. The observed influence of HRT on bone strength in the present study is larger than in previous RCT studies using DXA ${ }^{(19,20)}$ and CT technology ${ }^{(21)}$ where one to six years of use of HRT resulted in an increase of $2.5 \%$ to $4 \%$ in bending strength at a diaphyseal bone site whereas the difference between the co-twins in the present study was $9 \%$. Although the difference between the previous and our findings may derive from differences in the methodology and study design, it is also plausible that the larger differences found in our study results from longer duration of HRT. In addition, the role of HRT in preserving bone mass may become more important with increasing time from menopause as we found an annual increase of 2.6 to $2.8 \%$ post menopause in the intra-pair difference in bone strength.

The higher bending strength in the diaphyseal bone of the HRT users resulted from additional bone mineral mass throughout the cortex. The higher cortical volumetric BMD in HRT users compared to non-users in the present and a previous study among non-related women ${ }^{(24)}$ may 
reflect a lower level of intracortical porosity which normally increases with aging. ${ }^{(25)}$ After menopause, endocortical resorption accelerates leading to a reduction in cortical area and consequently in bone strength. ${ }^{(2,10,26)}$ In the present study, in the endocortical region, the cortex was larger in the HRT users than non-users. Therefore, our results support previous findings that HRT attenuates endocortical resorption, i.e. prevents bone loss on the inner surface of the cortex. ${ }^{(2,27)}$

It has been suggested that periosteal apposition takes place in women also after menopause and partly compensates the loss of strength following age-related mineral loss. ${ }^{(2)}$ Estrogen is considered to inhibit periosteal apposition. ${ }^{(10,11)}$ In the present study, the co-twins had similar cross-sectional areas, which suggests similar periosteal apposition in the HRT users and nonusers. This is in line with a longitudinal study by Szulc et al. using DXA in which no significant difference was found between the HRT users and non-users. However, some longitudinal studies using DXA-technology have found a smaller gain in diaphyseal bone diameter in HRT users than non-users supporting the inhibiting influence of HRT on periosteum. ${ }^{(21,22,26)}$ If HRT restricted periosteal apposition it could offset the positive effects of increased mineral density and mass on bone bending strength because small reductions in cross-sectional bone size substantially decrease bone bending strength.

The compressive strength of the epiphyseal bone sites was higher in the HRT users than nonusers. This was due to higher volumetric BMD since there was no difference between the cotwins in cross-sectional area, which together with total density determines compressive strength. The higher trabecular density in the HRT users may be due to the proposed ability of estrogen to prevent trabecular thinning ${ }^{(28)}$ and to preserve the trabecular structures. ${ }^{(29)}$ 
Apart from the observed influence on trabecular density, HRT also increased volumetric BMD in the cortex according to the radial distribution analysis.

It has been suggested that estrogen modulates the effect of mechanical loading on bone. ${ }^{(30)}$ The present study does not support this view. We found a similar difference $(\sim 10 \%)$ between the co-twins in bone mineral mass and strength in the body weight-loaded and non weightloaded bones, suggesting rather that HRT has a systemic effect on the skeleton. Further, the extra mineral mass was distributed somewhat uniformly across bone cross-sections increasing bone strength in all directions. In contrast, long-term exercise seems to increase bone mineral mass in the antero-posterior axis of a weight-loaded bone but not on the medio-lateral axis. ${ }^{(31)}$ Our findings thus support the view that estrogen and loading have independent effects on bone. $^{(32)}$

An important strength in this study were the design and the unique population-based data on genetically identical twin pairs which enabled investigation of the influence long-term HRT without an intervention. The design also intrinsically adjusts for both genetic and multiple environmental factors that are shared by the co-twins. Further, the measurement technique used made it possible to quantify the effects of HRT on volumetric BMD and macrostructure directly. This study has also some limitations. The measured bone sites in the lower limb are not clinically the most important ones. Also, without prospective follow-up data, it was not possible to monitor adherence to the use of HRT. Although the HRT products were heterogeneous in this study, the results are likely to be congruent with the effects of existing clinical practice in which HRT products are prescribed individually. 
In conclusion, long-term postmenopausal HRT preserves estimated bone strength by preventing bone mineral loss and by maintaining bone macrostructure. The extra mineral preserved using HRT is distributed evenly across the bone's cross-section. Thus, HRT prevents adverse effects of menopause on the skeleton which predispose postmenopausal women to fractures. 


\section{ACKNOWLEDGEMENTS}

This study has received grant support from the Finnish Ministry of Education, the Academy of Finland, the Finnish Cultural Foundation, Yrjö Jahnsson Foundation and National Graduate School of Musculoskeletal Disorders and Biomaterials. 


\section{REFERENCES}

1. Riggs BL, Khosla S, Melton LJ,3rd 2002 Sex steroids and the construction and conservation of the adult skeleton. Endocr Rev 23:279-302.

2. Szulc P, Seeman E, Duboeuf F, Sornay-Rendu E, Delmas PD 2006 Bone fragility: failure of periosteal apposition to compensate for increased endocortical resorption in postmenopausal women. J Bone Miner Res 21:1856-1863.

3. van der Meulen MC, Jepsen KJ, Mikic B 2001 Understanding bone strength: size isn't everything. Bone 29:101-104.

4. LaCroix AZ, Beck TJ, Cauley JA, Lewis CE, Bassford T, Jackson R, Wu G, Chen Z 2010 Hip structural geometry and incidence of hip fracture in postmenopausal women: what does it add to conventional bone mineral density? Osteoporos Int 21:919-929.

5. Riggs LB, Parfitt AM 2005 Drugs Used to Treat Osteoporosis: The Critical Need for a Unifrom Nomenclature Based on Their Action on Bone Remodeling. J Bone Miner Res 20:177-184.

6. Cauley JA, Robbins J, Chen Z, Cummings SR, Jackson RD, LaCroix AZ, LeBoff M, Lewis CE, McGowan J, Neuner J, Pettinger M, Stefanick ML, Wactawski-Wende J, Watts NB, Women's Health Initiative Investigators 2003 Effects of estrogen plus progestin on risk of fracture and bone mineral density: the Women's Health Initiative randomized trial. JAMA 290:1729-1738.

7. Cummings SR, Ettinger B, Delmas PD, Kenemans P, Stathopoulos V, Verweij P, Mol-Arts M, Kloosterboer L, Mosca L, Christiansen C, Bilezikian J, Kerzberg EM, Johnson S, 
Zanchetta J, Grobbee DE, Seifert W, Eastell R, LIFT Trial Investigators 2008 The effects of tibolone in older postmenopausal women. N Engl J Med 359:697-708.

8. Kim B, Mosekilde, L, Duan Y, Zhang X, Tornvig L, Thomsen JS, Seeman E 2003 The structural and hormonal basis of sex differences in peak appendicular bone strength in rats. $\mathrm{J}$ Bone Miner Res 18:150-155.

9. Samuels A, Perry MJ, Gibson R, Tobias JH 2001 Effects of combination therapy with PTH and 17ß-estradiol on long bones of female mice. Calcif Tissue Int 69:164-170.

10. Seeman E 2003 Periosteal bone formation--a neglected determinant of bone strength. $\mathrm{N}$ Engl J Med 349:320-323.

11. Vanderschueren D, Venken K, Ophoff J, Bouillon R, Boonen S 2006 Clinical Review: Sex steroids and the periosteum--reconsidering the roles of androgens and estrogens in periosteal expansion. J Clin Endocrinol Metab 91:378-382.

12. Komulainen M, Kröger H, Tuppurainen MT, Heikkinen AM, Alhava E, Honkanen R, Jurvelin J, Saarikoski S 1999 Prevention of femoral and lumbar bone loss with hormone replacement therapy and vitamin D3 in early postmenopausal women: a population-based 5year randomized trial. J Clin Endocrinol Metab 84:546-552.

13. Mikkola TM, Sipilä S, Rantanen T, Sievanen H, Suominen H, Kaprio J, Koskenvuo M, Kauppinen M, Heinonen A 2008 Genetic and environmental influence on structural strength of weight-bearing and non-weight-bearing bone: a twin study. J Bone Miner Res 23:492-498.

14. Mikkola TM, Sipilä S, Rantanen T, Sievänen H, Suominen H, Tiainen K, Kaprio J, Koskenvuo M, Kauppinen M, Heinonen A 2009 Muscle cross-sectional area and structural 
bone strength share genetic and environmental effects in older women. J Bone Miner Res 24:338-345.

15. Kaprio J, Koskenvuo M 2002 Genetic and environmental factors in complex diseases: the older Finnish Twin Cohort. Twin Res 5:358-365.

16. Tiainen K, Sipilä S, Alén M, Heikkinen E, Kaprio J, Koskenvuo M, Tolvanen A, Pajala S, Rantanen T 2004 Heritability of maximal isometric muscle strength in older female twins. J Appl Physiol 96:173-180.

17. Ronkainen PH, Kovanen V, Alén M, Pöllänen E, Palonen EM, Ankarberg-Lindgren C, Hämäläinen E, Turpeinen U, Kujala UM, Puolakka J, Kaprio J, Sipilä S 2009 Postmenopausal hormone replacement therapy modifies skeletal muscle composition and function: a study with monozygotic twin pairs. J Appl Physiol 107:25-33.

18. Ankarberg-Lindgren C, Norjavaara E 2008 A purification step prior to commercial sensitive immunoassay is necessary to achieve clinical usefulness when quantifying serum 17beta-estradiol in prepubertal children. Eur J Endocrinol 158:117-124.

19. Bjørnerem A, Straume B, Midtby M, Fønnebø V, Sundsfjord J, Svartberg J, Acharya G, Øian P, Berntsen GK 2004 Endogenous sex hormones in relation to age, sex, lifestyle factors, and chronic diseases in a general population: the Tromso Study. J Clin Endocrinol Metab 89:6039-6047.

20. Grimby G 1986 Physical activity and muscle training in the elderly. Acta Med Scand Suppl 711:233-237.

21. Chen Z, Beck TJ, Cauley JA, Lewis CE, LaCroix A, Bassford T, Wu G, Sherrill D, Going S 2008 Hormone therapy improves femur geometry among ethnically diverse 
postmenopausal participants in the Women's Health Initiative hormone intervention trials. J Bone Miner Res 23:1935-1945.

22. Greenspan SL, Beck TJ, Resnick NM, Bhattacharya R, Parker RA 2005 Effect of hormone replacement, alendronate, or combination therapy on hip structural geometry: a 3year, double-blind, placebo-controlled clinical trial. J Bone Miner Res 20:1525-1532.

23. Cheng S, Sipilä S, Taaffe DR, Puolakka J, Suominen H 2002 Change in bone mass distribution induced by hormone replacement therapy and high-impact physical exercise in post-menopausal women. Bone 31:126-135.

24. Uusi-Rasi K, Beck TJ, Sievänen H, Heinonen A, Vuori I 2003 Associations of hormone replacement therapy with bone structure and physical performance among postmenopausal women. Bone 32:704-710.

25. Cooper DM, Thomas CD, Clement JG, Turinsky AL, Sensen CW, Hallgrimsson B 2007 Age-dependent change in the 3D structure of cortical porosity at the human femoral midshaft. Bone 40:957-965.

26. Russo CR, Lauretani F, Bandinelli S, Bartali B, Di Iorio A, Volpato S, Guralnik JM, Harris T, Ferrucci L 2003 Aging bone in men and women: beyond changes in bone mineral density. Osteoporos Int 14:531-538.

27. Beck TJ, Stone KL, Oreskovic TL, Hochberg MC, Nevitt MC, Genant HK, Cummings SR 2001 Effects of current and discontinued estrogen replacement therapy on hip structural geometry: the study of osteoporotic fractures. J Bone Miner Res 16:2103-2110.

28. Cano A, Dapia S, Noguera I, Pineda B, Hermenegildo C, del Val R, Caeiro JR, GarciaPerez MA 2008 Comparative effects of 17beta-estradiol, raloxifene and genistein on bone 3D 
microarchitecture and volumetric bone mineral density in the ovariectomized mice. Osteoporos Int 19:793-800.

29. Pajamäki I, Sievänen H, Kannus P, Jokihaara J, Vuohelainen T, Järvinen TL 2008 Skeletal effects of estrogen and mechanical loading are structurally distinct. Bone 43:748-757.

30. Lanyon L, Skerry T 2001 Postmenopausal osteoporosis as a failure of bone's adaptation to functional loading: a hypothesis. J Bone Miner Res 16:1937-1947.

31. Ma H, Leskinen T, Alén M, Cheng S, Sipilä S, Heinonen A, Kaprio J, Suominen H, Kujala UM 2009 Long-term leisure time physical activity and properties of bone: a twin study. J Bone Miner Res 24:1427-1433.

32. Järvinen TL, Kannus P, Sievänen H 2003 Estrogen and bone--a reproductive and locomotive perspective. J Bone Miner Res 18:1921-1931. 
Table 1. Self-reported illnesses, gynecological surgical operations, and fractures in 24 hormone replacement (HRT) users and their non-user monozygotic co-twins.

\begin{tabular}{lll}
\hline & HRT & HRT non-users \\
\hline Hypertension & 5 & 5 \\
Other cardiovascular diseases ${ }^{1}$ & 1 & 5 \\
History of cerebral ischemia & 1 & 1 \\
Type II diabetes & 0 & 1 \\
History of cancer ${ }^{2}$ & 1 & 4 \\
Hysterectomy and ovariectomy & 7 & 2 \\
Hysterectomy & 4 & 1 \\
Fractures after menopause ${ }^{3}$ & 0 & 5 \\
$\begin{array}{l}{ }^{1} \text { Cardiac insufficiency, history of myocardial infarction, coronary artery disease, or } \\
\text { arrhythmia }\end{array}$ \\
${ }^{2}$ One basalioma in both groups, one melanoma, one lymphoma, one renal cancer \\
${ }^{3}$ Phalangeal fractures omitted
\end{tabular}


Table 2 Body characteristics, serum hormone concentrations, and properties of bone of 24 hormone replacement (HRT) users and their non-user monozygotic co-twins

\begin{tabular}{|c|c|c|c|c|c|}
\hline \multirow[t]{2}{*}{ Variable } & \multicolumn{2}{|c|}{ HRT users } & \multicolumn{2}{|c|}{ HRT non-users } & \multirow[b]{2}{*}{$\mathbf{p}^{\mathrm{a}}$} \\
\hline & Mean & (SD) & Mean & (SD) & \\
\hline Body height, cm & 162 & $(5.5)$ & 161 & $(5.1)$ & $0.13^{b}$ \\
\hline Body mass, kg & 71.2 & $(9.6)$ & 72.6 & $(12.5)$ & 0.55 \\
\hline Lean body mass, $\mathrm{kg}$ & 48.0 & $(3.4)$ & 47.5 & $(4.2)$ & 0.52 \\
\hline Body fat, $\mathrm{kg}$ & 23.2 & $(7.8)$ & 25.1 & $(9.9)$ & 0.28 \\
\hline Total estradiol, pmol/1 & 173 & (199) & 26.2 & $(20.1)$ & $<0.001^{\mathrm{b}}$ \\
\hline Free estradiol, pmol/1 & 3.04 & $(2.82)$ & 0.61 & $(0.46)$ & $<0.001^{\mathrm{b}}$ \\
\hline $\mathrm{SHBG}, \mathrm{nmol} / 1$ & 75.7 & (44) & 56.5 & $(28.1)$ & 0.025 \\
\hline \multicolumn{6}{|l|}{ Tibial shaft $(n=21)$} \\
\hline $\mathrm{BMC}(\mathrm{mg} / \mathrm{mm})$ & 365 & $(28)$ & 333 & (44) & $<0.001$ \\
\hline ToA $\left(\mathrm{mm}^{2}\right)$ & 490 & (49) & 482 & (39) & 0.19 \\
\hline $\mathrm{CoA}\left(\mathrm{mm}^{2}\right)$ & 299 & $(22)$ & 280 & (32) & $0.013^{b}$ \\
\hline $\operatorname{MaA}\left(\mathrm{mm}^{2}\right)$ & 93.1 & $(27)$ & 99.8 & $(28)$ & 0.061 \\
\hline CoA/ToA & 0.61 & $(0.05)$ & 0.58 & $(0.08)$ & $0.039^{\mathrm{b}}$ \\
\hline $\mathrm{CoD}\left(\mathrm{mg} / \mathrm{cm}^{3}\right)$ & 1049 & (46) & 1002 & $(72)$ & $<0.001$ \\
\hline BSIbend (index) & 1.76 & $(0.20)$ & 1.63 & $(0.21)$ & 0.005 \\
\hline \multicolumn{6}{|l|}{ Distal tibia $(n=23)$} \\
\hline $\mathrm{BMC}(\mathrm{mg} / \mathrm{mm})$ & 276 & (34) & 255 & (46) & $0.002^{b}$ \\
\hline ToA $\left(\mathrm{mm}^{2}\right)$ & 1004 & $(102)$ & 1012 & $(122)$ & 0.54 \\
\hline $\mathrm{ToD}\left(\mathrm{mg} / \mathrm{cm}^{3}\right)$ & 276 & $(30)$ & 255 & $(51)$ & 0.002 \\
\hline $\operatorname{TrD}\left(\mathrm{mg} / \mathrm{cm}^{3}\right)$ & 218 & (27) & 202 & (45) & 0.022 \\
\hline
\end{tabular}



BSIcomp $\left(\mathrm{g}^{2} / \mathrm{cm}^{4}\right)$
0.77
$(0.16)$
0.67
$(0.23)$
0.001

Distal radius $(\mathrm{n}=\mathbf{2 2})$

$\begin{array}{lccccc}\text { BMC }(\mathrm{mg} / \mathrm{mm}) & 106 & (14) & 97 & (19) & 0.001 \\ \operatorname{ToA}\left(\mathrm{mm}^{2}\right) & 329 & (51) & 328 & (54) & 0.71 \\ \operatorname{ToD}\left(\mathrm{mg} / \mathrm{cm}^{3}\right) & 329 & (59) & 303 & (75) & 0.002 \\ \operatorname{TrD}\left(\mathrm{mg} / \mathrm{cm}^{3}\right) & 178 & (31) & 157 & (50) & 0.009 \\ \text { BSIcomp }\left(\mathrm{g}^{2} / \mathrm{cm}^{4}\right) & 0.35 & (0.09) & 0.30 & (0.12) & 0.001\end{array}$

SHBG, sex hormone-binding globulin; BMC, bone mineral mass; ToA, total cross-sectional area; $\mathrm{CoA}$, cortical cross-sectional area; $\mathrm{MaA}$, marrow cavity area; $\mathrm{CoD}$, cortical volumetric bone mineral density: BSIbend, bending strength index (section modulus); ToD, total volumetric bone mineral density; $\mathrm{TrD}$, trabecular volumetric bone mineral density, BSIcomp, compressive strength index

${ }^{\mathrm{a}} \mathrm{p}$-value of the paired t-test unless indicated otherwise

${ }^{b}$-value of the Wilcoxon signed ranks test 


\section{FIGURE LEGENDS}

Fig. 1. Properties of bone in women using HRT compared to their monozygotic non-using cotwins. The squares represent intra-pair differences $[$ IPD $\%=($ HRT user - nonuser $) /$ nonuser * $100]$, and the error bars represent 95\% confidence intervals for IPD\%. (BMC, bone mineral mass; ToA, total cross-sectional area; CoA, cortical cross-sectional area; MaA, marrow cavity area; CoD, cortical volumetric bone mineral density: BSIbend, bending strength index (section modulus); ToD, total volumetric bone mineral density; $\operatorname{TrD}$, trabecular volumetric bone mineral density, BSIcomp, compressive strength index)

Fig. 2. Mean radial distributions of bone density from the centre of bone mass to the outer edge of the bone for HRT-using co-twins (solid line with squares) and non-using co-twins (dotted line with diamonds). In the tibial shaft, bone marrow area is excluded. ${ }^{*} \mathrm{p}<0.05$ (paired t-test)

Fig. 3. Mean polar distributions of bone mass as 72 sectors around the centre of bone mass for HRT-using co-twins (solid line) and non-using co-twins (dotted line). Axes show anterior (A), posterior (P), medial (M), and lateral (L) directions. In the bar charts, mean intra-pair difference $[\mathrm{IPD} \%=($ HRT user - nonuser $) /$ nonuser $* 100]$ in bone mineral mass is presented for 8 sectors. Error bars are 95\% confidence intervals. 


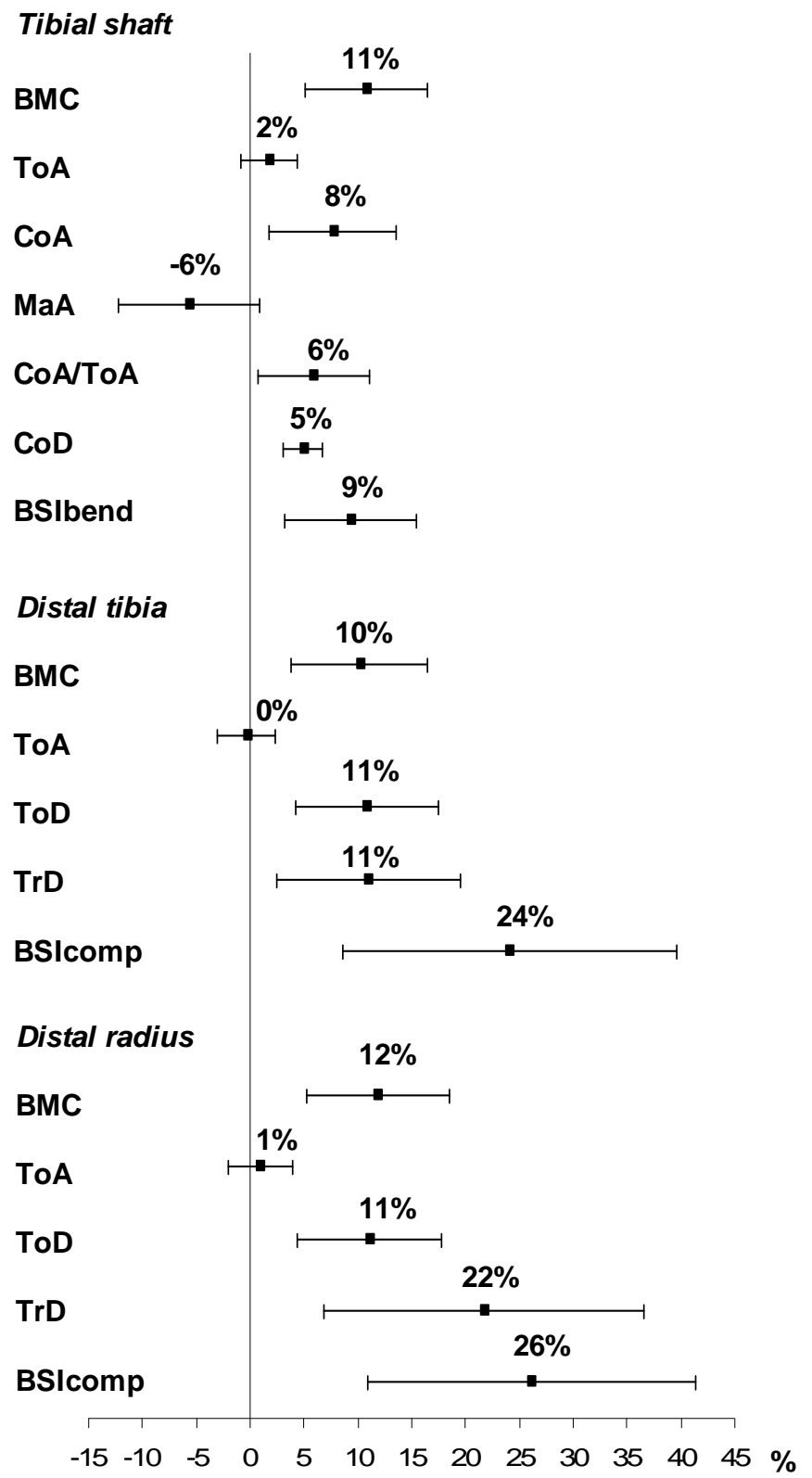


Tibial shaft
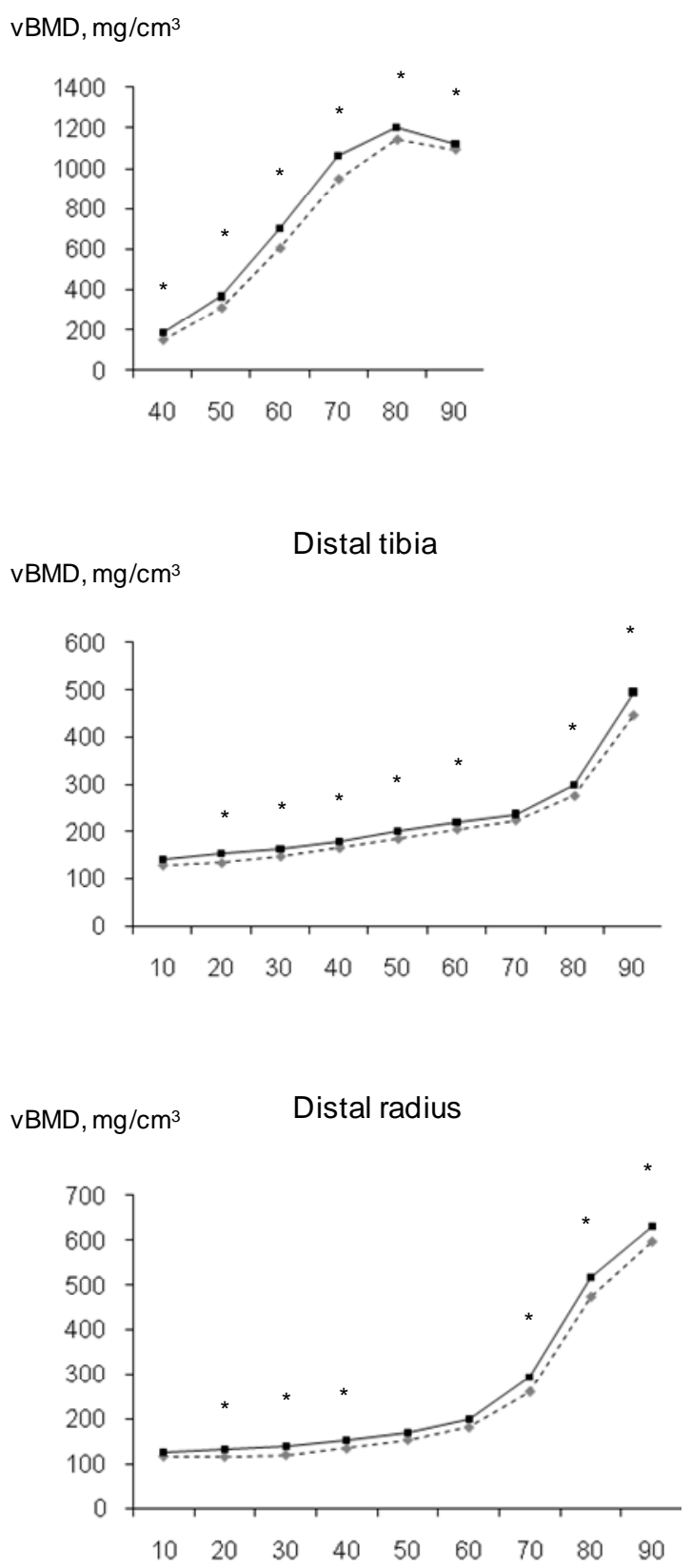

Relative distance from the center of mass, $\%$ 

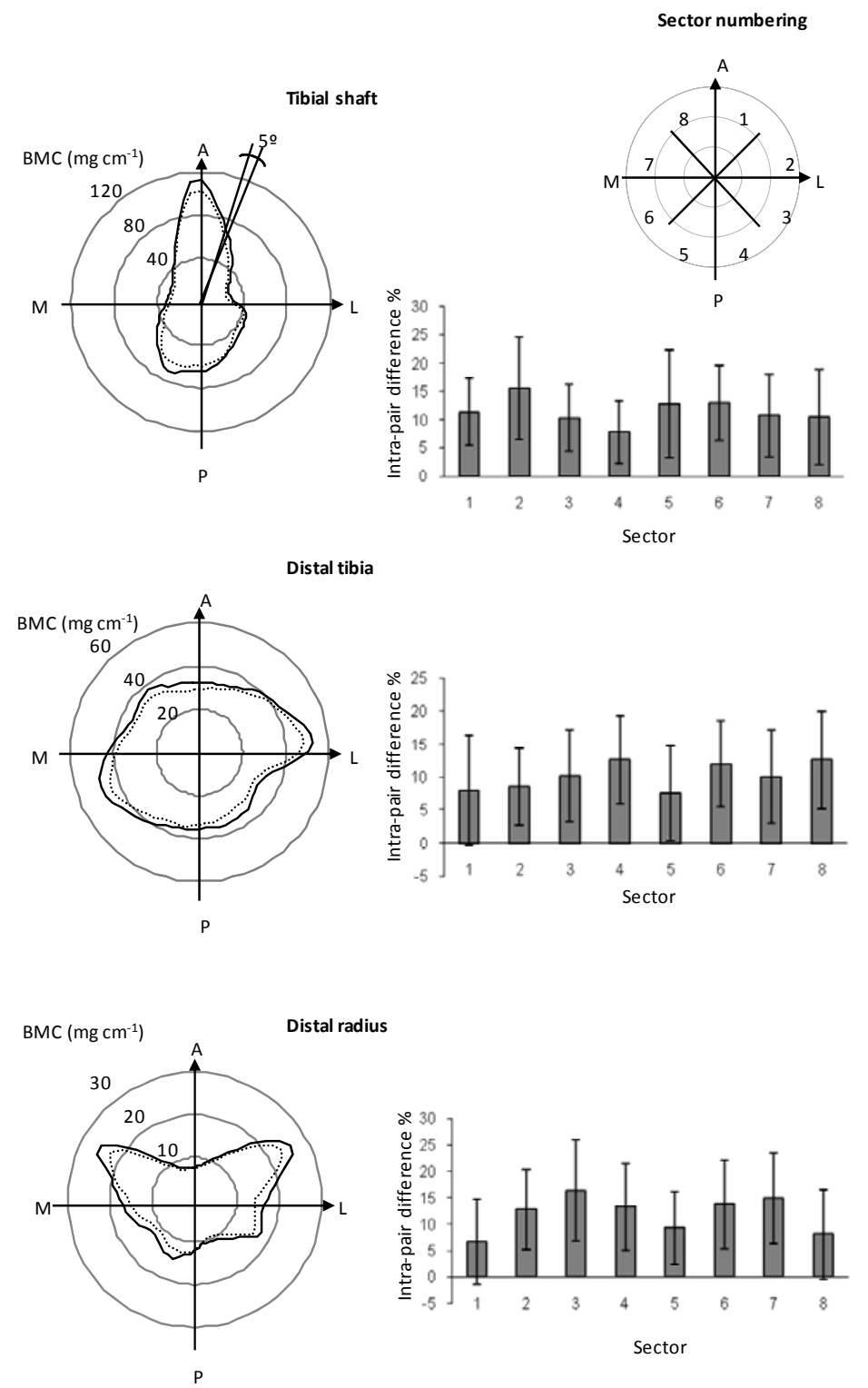